\title{
Nucleic Acids-Based Therapeutics in the Battle Against Pathogenic Viruses
}

\author{
Joost Haasnoot and Ben Berkhout
}

\begin{abstract}
Contents

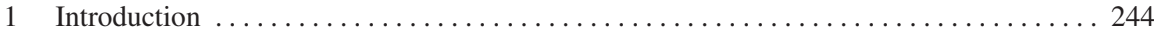

2 Antisense-Based Antiviral Therapeutics . . . . . . . . . . . . . . . . . . . . . . 246

3 Ribozymes as Antiviral Therapeutics . . . . . . . . . . . . . . . . . . . . . . . . 248

4 Aptamers and Decoy RNAs as Antiviral Therapeutics . . . . . . . . . . . . . . . . . . . . 249

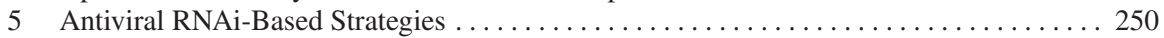

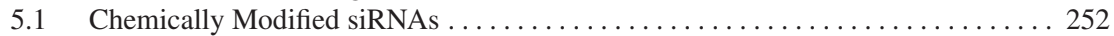

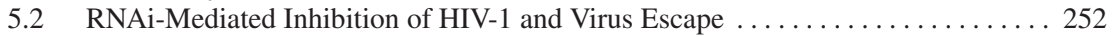

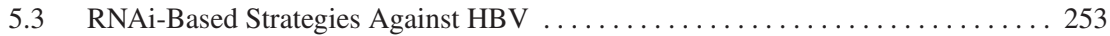

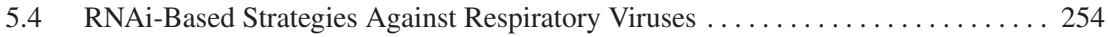

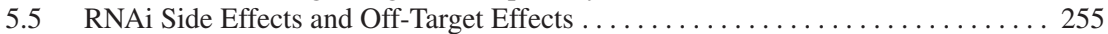

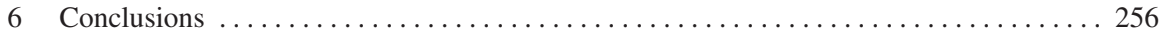

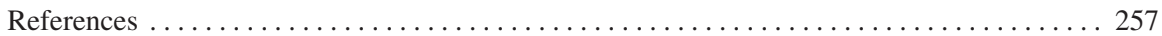

Abstract For almost three decades, researchers have studied the possibility to use nucleic acids as antiviral therapeutics. In theory, compounds such as antisense oligonucleotides, ribozymes, DNAzymes, and aptamers can be designed to trigger the sequence-specific inhibition of particular mRNA transcripts, including viral genomes. However, difficulties with their efficiency, off-target effects, toxicity, delivery, and stability halted the development of nucleic acid-based therapeutics that can be used in the clinic. So far, only a single antisense drug, Vitravene for the treatment of CMV-induced retinitis in AIDS patients, has made it to the clinic. Since the discovery of RNA interference (RNAi), there is a renewed interest in the development of nucleic acid-based therapeutics. Antiviral RNAi approaches are highly effective in vitro and in animal models and are currently being tested in clinical trials. Here we give an overview of antiviral nucleic acid-based therapeutics. We focus on antisense and RNAi-based compounds that have been shown to be effective in animal model systems.

\section{B. Berkhout $(\bowtie)$}

Laboratory of Experimental Virology, Department of Medical Microbiology,

Center for Infection and Immunity Amsterdam (CINIMA), Academic Medical Center of the University of Amsterdam K3-110, Meibergdreef 15, 1105 AZ Amsterdam, The Netherlands b.berkhout@amc.uva.nl

H.-G. Kräusslich, R. Bartenschlager (eds.), Antiviral Strategies, Handbook of Experimental 


\section{Abbreviations}

$\begin{array}{ll}A I D S & \text { Acquired immune deficiency syndrome } \\ A A V & \text { Adeno-associated virus } \\ C M V & \text { Cytomegalovirus } \\ H I V-1 & \text { Human immunodeficiency virus type 1 } \\ H B V & \text { Hepatitis B virus } \\ H C V & \text { Hepatitis C virus } \\ R S V & \text { Respiratory syncytial virus } \\ \text { SARS } & \text { Severe acute respiratory syndrome } \\ R N A i & \text { RNA interference } \\ \text { SiRNA } & \text { Small interfering RNA } \\ \text { ShRNA } & \text { Short hairpin RNA } \\ R I S C & \text { RNA-induced silencing complex } \\ P S & \text { Phosphorothioate } \\ O M e & \text { 2'-O-Methyl-RNA } \\ M O E & \text { 2'-O-Methoxy-ethyl-RNA } \\ P N A & \text { Peptide nucleic acid } \\ L N A & \text { Locked nucleic acid } \\ M F & \text { Morpholino phosphoroamidates }\end{array}$

\section{Introduction}

The most efficacious method to avoid infection with pathogenic viruses is immunization of individuals with prophylactic vaccines. However, for most viruses such vaccines are not available. Antiviral drugs that block replicating virus in infected individuals are therefore of great importance in the battle against virus infections. Ideally, these drugs should induce strong and specific inhibition of virus replication without affecting cellular processes. This type of drugs remained fiction until Zamecnik and Stephenson reported the sequence-specific inhibition of Rous sarcoma virus replication by antisense DNA oligonucleotides in 1978 (Zamecnik and Stephenson 1978). This paper and subsequent reports on the sequence-specific knock-down of genes by antisense technology made a big impression on the scientific community that is comparable to the current RNAi boom. However, the development of antisense-based therapeutics stuttered and almost came to a stop because of problems with toxicity of the oligonucleotides, their instability in serum, and the problem of delivery to the right target cells. A new generation of nucleic acid-based antiviral compounds were subsequently developed, such as ribozymes, DNAzymes, and decoy RNAs, but they faced similar problems. Some of the problems could be solved using chemically modified nucleic acids instead of normal DNA/RNA oligonucleotides. For example, modifications such as phosphorothioate (PS) DNA or $2^{\prime}$ - $O$-methyl-RNA (OMe) increased the affinity of the oligonucleotides for their target sequence and increased serum stability (see Fig. 1). 
<smiles>COP(=O)([O-])OC1CC2COC1C2</smiles>

DNA<smiles>[B]C1OC2CC3OP(=O)(OC)OC3C1C2</smiles>

Phosphorothioate DNA (PS)<smiles>[B]C1OC2OC1C(OP(=O)([O-])OC)C2C</smiles>

RNA

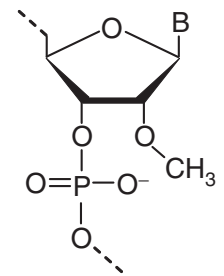

2'-O-methyl RNA (OMe)<smiles>[B]C1OC2C(C)C(OP(=O)([O-])OC)C1C2OC</smiles>

2'-O-methoxy-ethyl RNA (MOE)

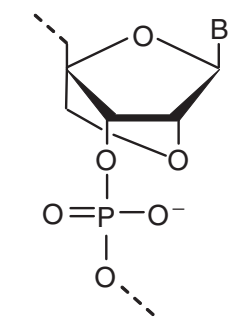

Locked nucleic acid (LNA)

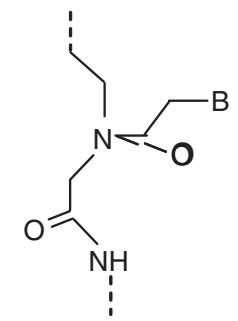

Peptide nucleic acid (PNA)<smiles>[B]C1CN(OP(=O)(OC)N(C)C)CC(C)O1</smiles>

Morpholino phosphoroamidate (MF)

Fig. 1 Chemical structures of backbone modifications used in therapeutic nucleic acid analogs. Shown are the unmodified DNA/RNA chemical structures in addition to a selection of first (PS), second (OMe, MOE), and third generation (PNA, LNA, MF) nucleic acid modifications

New hope for nucleic acid-based therapeutics came in 2001 when Elbashir and coworkers showed that synthetic small interfering RNAs (siRNAs) induced sequence-specific knock-down of genes in mammalian cells without triggering the interferon response (Elbashir et al. 2001). RNAi was immediately recognized as a potentially powerful new tool to combat a variety of viruses. Indeed, profound inhibition has been reported for many important human pathogenic viruses, and several potential antiviral siRNA compounds are currently being tested in clinical trials (Haasnoot et al. 2007). Despite these promising data, it is becoming increasingly clear that some of the problems that were earlier encountered by antisense drugs also apply to RNAi-based therapeutics. Although RNAi-mediated silencing is highly sequence-specific, therapeutic siRNAs can cause unwanted silencing of cellular mRNAs (Birmingham et al. 2006; Fedorov et al. 2006; Jackson et al. 2003; 
Kleinman et al. 2008). In addition, synthetic siRNAs are also subject to degradation in vivo by nuclease activity. Besides side effects and instability, the efficient and specific delivery of the RNAi inducers to the target cell still requires optimization. Here we summarize the current status of nucleic acid-based antiviral therapeutics. The focus will be on antiviral strategies using antisense and RNAi technology. Additionally, antiviral ribozymes and aptamers will be discussed briefly, with a focus on recent studies. Gene therapy approaches and delivery systems are the subject of Chapter 11 of this book.

\section{Antisense-Based Antiviral Therapeutics}

Antisense technology is based on the sequence-specific binding of antisense DNA oligonucleotides to complementary sequences in the target mRNA (Van Aerschot 2006). After binding to the target RNA, the oligonucleotide can block translation via steric hindrance of the elongating ribosome or induce RNA cleavage by activation of RNase $\mathrm{H}$, the enzyme that specifically recognizes DNA/RNA duplexes. Although antisense technology can induce profound sequence-specific inhibition of gene expression in some settings, major problems include instability, delivery, and unwanted side effects of the oligonucleotides. Chemical modification of the oligonucleotides was found to improve the efficacy (Fig. 1).

The first generation of chemical modification was designed to enhance nuclease resistance of the oligonucleotide in serum (Stein et al. 1997). The PS modification, in which the oxygen atom in the DNA backbone is replaced by a sulfur atom, has been widely used. The advantage of the PS-modified oligonucleotides is that it allows RNase $\mathrm{H}$ cleavage of the target sequence. A disadvantage is that the PS modification introduces a negative charge that causes nonspecific interactions with other molecules, for example, cellular proteins. As a result, PS-modified oligonucleotides are notorious for inducing severe side effects that are toxic for cells. A well-known example of an antiviral PS-modified oligonucleotide is Vitravene for treatment of cytomegalovirus (CMV)-induced retinitis in AIDS patients. This is a 21-nucleotide that inhibits the expression of viral proteins from the major immediate-early transcriptional unit (Vitravene study group, 2002). Until now, Vitravene is the only antisense-based drug that has received FDA approval and is used in the clinic. Although Vitravene provides a marked reduction of disease severity, the compound is currently not widely used mainly because AIDS patients on antiretroviral therapy rarely develop CMV-induced retinitis.

Second generation oligonucleotides are based on modifications of the sugar ring. For example, OMe and 2'-O-methoxy-ethyl (MOE) modifications (Fig. 1) increase the stability of the oligonucleotide and the affinity for the target mRNA when compared to PS-modified oligonucleotides. In contrast to the PS modification, the OMe and MOE-modified oligonucleotides do not allow cleavage by RNase $\mathrm{H}$, but they rather block translation via steric hindrance of the ribosome during translation. For optimal activity, the oligonucleotide has to be targeted to sequences that are at or 
near the translation initiation site. The OMe modification has also been used in combination with PS modifications in the so-called gap-mers, in which the central nucleotides carry the PS modification and the flanking nucleotides the OMe modification (Monia et al. 1993). This approach combines the benefits of both the first and second generation modifications. An example of a second generation-modified antiviral oligonucleotide is GEM-92, which was developed by Hybridon (currently discontinued). GEM-92 is a gap-mer, with OMe modified flanks and PS modified central sequences (Turner et al. 2006).

Third generation oligonucleotides are DNA and RNA analogues with extensive modifications of the phosphate backbone and the sugar ring. Examples are peptide nucleic acids (PNA), in which the backbone has been replaced by a peptide linker, morpholino phosphoroamidates (MF), and locked nucleic acids (LNA) (Fig. 1) (Iversen 2001; Larsen et al. 1999; Petersen and Wengel 2003). These modifications provide further improved nuclease resistance and target affinity. In addition, the PNA and MF modifications allow enhanced cellular uptake. To combine all benefits, third generation modifications can be used in combination with unmodified residues in chimaeric gap-mers. LNA modifications are widely used in various applications. It introduces a $2^{\prime}-\mathrm{O}, 4^{\prime} \mathrm{C}$-methylene bridge that locks the ribose in a $\mathrm{C}^{\prime}$ '-endo conformation. This "locked" conformation results in a strong increase in the affinity for the target mRNA (Petersen and Wengel 2003). LNA modifications were reported to cause less toxic side effects when compared to the first and second generation modifications (Wahlestedt et al. 2000). However, LNA-modified oligonucleotides were recently shown to induce profound toxicity in hepatocytes in mice (Swayze et al. 2007).

Despite these intense efforts to test different chemical modifications, there is so far little success in developing potent and safe antivirals. For hepatitis $\mathrm{C}$ virus (HCV), McHutchison et al. reported in vivo side effects of a 20-nucleotide PSmodified oligonucleotide (ISIS-14803) (McHutchison et al. 2006). In a test group of 28 patients, only 3 patients responded to the treatment by a reduction in the HCV viral load. The researchers concluded that further studies are needed to evaluate this novel agent and its side effects. Previously, ISIS Pharmaceuticals reported a $3.8 \mathrm{log}$ reduction in plasma virus in patients with chronic HCV infection, using ISIS-14803 (www.isispharm.com).

Warfield et al. reported profound inhibition of Ebola virus in mice and rhesus macaques using antisense MF oligonucleotides (Warfield et al. 2006). Combination of several oligonucleotides targeting mRNAs for VP24, VP35, and the RNA polymerase protected the animals, both therapeutically and prophylactically. The modified oligonucleotides protected $75 \%$ of the macaques from lethal Ebola virus infection. Similarly, MF oligonucleotides were recently found to profoundly inhibit the murine hepatitis coronavirus. Treatment protected mice against a normally lethal viral challenge, but there were some indications of toxic effects (Burrer et al. 2007).

A different antiviral approach uses intracellular expression of unmodified antisense molecules corresponding to viral sequences. Such an intracellular immunization approach may require a gene therapy protocol to deliver the antiviral transgene. In a phase I clinical trial, Levine et al. used intracellularly expressed 
antisense transcripts to inhibit HIV-1 replication. The advantage of using extended antisense sequences is that multiple viral sites are targeted simultaneously (Levine et al. 2006). A conditionally replicating lentiviral vector was used to transduce CD4 $\mathrm{T}$ cells ex vivo for intracellular expression of antisense sequences against the HIV-1 envelope gene. The modified CD4 T cells were infused back into the same patient and were apparently well tolerated in all patients. One of the five patients showed a sustained decrease in viral load (Levine et al. 2006). Alternatively, short antisense molecules against sequences in the HIV-1 gag gene were shown to inhibit virus replication in transduced CEM cells (Gu et al. 2006).

\section{Ribozymes as Antiviral Therapeutics}

Ribozymes represent a class of natural RNAs that catalyse RNA cleavage and ligation reactions as well as peptide bond formation. In most cases, these reactions are self-processing events that take place in a sequence-specific manner. It was found, however, that ribozymes can be designed to specifically cleave other RNA molecules in trans by modification of the substrate recognition domains. Because of their sequence specificity and multiple turnover or catalytic properties, such ribozymes have been extensively studied as potential therapeutics (Peracchi 2004). Of the nine classes of ribozymes, the hammerhead and hairpin ribozymes have received a great deal of attention. These ribozymes are relatively small (50-100 nucleotides) and can direct cleavage of single-stranded target RNA. Many ribozymes that are used in therapeutic applications have been improved by in vitro selection procedures, in which the most active molecules were selected from partially randomized sequences. In vitro selection has also generated DNAzymes that structurally and functionally resemble ribozymes, but that have a DNA instead of RNA backbone (Santoro and Joyce 1997). These DNAzymes can have a catalytic activity similar to that of ribozymes, but they are more stable in vivo.

Therapeutic ribozymes have been used both as synthetic RNA that is transfected into cells and as intracellularly expressed RNA. Because unmodified ribozymes are rapidly degraded in serum, synthetic ribozymes require chemical modification to extend the half life and to improve the therapeutic potential of ribozymes (Gonzalez-Carmona et al. 2006; Jakobsen et al. 2007). Antiviral ribozymes have been extensively tested in gene therapy settings (Haasnoot et al. 2007). In these studies, the ribozyme is placed under control of a suitable promoter and inserted in a vector to transduce the target cells. Anti-HIV-1 ribozymes have been studied in several clinical trials. Macpherson et al. have tested an anti-tat ribozyme in a phase I clinical trial (Macpherson et al. 2005). In preclinical studies, this ribozyme was shown to decrease HIV-1 replication and virus-induced pathogenicity in T cell lines and peripheral blood T-lymphocytes. In the clinical trial, CD4 ${ }^{+}$T-lymphocytes were transduced ex vivo using a retroviral vector for expression of the ribozyme. The transduced cells were given back to the HIV-positive patients. This gene therapy was found to be safe and was shown to inhibit HIV-1 replication. Li and coworkers have 
used a ribozyme in combination with an siRNA and a decoy RNA to inhibit HIV-1 replication ( $\mathrm{Li}$ et al. 2003, 2005b). The ribozyme is targeted towards the mRNA for the cellular CCR5 protein, which functions as essential coreceptor for HIV-1 entry. The decoy is the viral TAR RNA hairpin structure, which is supposed to bind the viral Tat protein and cellular cofactors that are needed for viral gene expression. $\mathrm{CD} 4^{+}$hematopoietic progenitor cells were also transduced with a retroviral vector for the expression of the ribozyme. These cells differentiated normally into mature macrophages and showed significant resistance to viral infection. When the ribozyme was used in combination with the Tat/Rev siRNA and the TAR decoy, the transduced cells showed long-term viral resistance in vitro and the transduced hematopoietic stem cells developed normally into T cells in SCID-hu mice. These cells were able to resist HIV-1 infection ex vivo (Anderson et al. 2007).

\section{Aptamers and Decoy RNAs as Antiviral Therapeutics}

In contrast to other nucleic acid-based antiviral strategies, decoy RNAs or small RNA/DNA aptamers act via specific binding to a viral target protein rather than to viral RNAs. The interaction of the decoy with the target protein prevents it from being active and hence blocks virus replication (James 2007). The HIV-1 TAR decoy described earlier is a well-known example. Another decoy RNA to inhibit HIV-1 corresponds to the Rev responsive element (RRE). Interaction of the RRE with the viral Rev protein is required for the transport of single and unspliced viral RNAs from the nucleus to the cytoplasm. Overexpression of an RRE decoy sequesters the Rev protein, thereby blocking nuclear export of viral RNAs and thus virus replication (Bahner et al. 1996). This RRE decoy has earlier been tested in a phase I clinical trial in which $\mathrm{CD}_{3}{ }^{+}$stem cells were transduced ex vivo with a retroviral vector for the expression of the RNA inhibitor (Kohn et al. 1999). There was no evidence that expression of the decoy affected cell function, but there were also no detectable changes in the subject's plasma HIV-1 level.

Besides overexpression of a decoy RNA that resembles a natural viral RNA motif, there is also an interest in the use of artificial small nucleic acid aptamers that have a high affinity for a certain target protein. These aptamers were identified in large randomized pools of sequences by repetitive rounds of selection for binding with the highest affinity to the target protein (James 2007). The early targets for aptamer development were viral polymerases. For example, potent aptamers were selected that inhibit HIV-1 reverse transcriptase (RT) and HCV RNA polymerase (Bellecave et al. 2003; Burke et al. 1996; Tuerk et al. 1992). These aptamers are not similar to any viral sequences, indicating that the high affinity binding aptamers do not necessarily have to be analogues of natural substrates. It has been shown that HIV-1-specific RT aptamers can potently inhibit RT enzymes from multiple HIV-1 subtypes, suggesting that these aptamers can provide broad protection (Held et al. 2007). However, naturally resistant virus strains exist against some aptamers, which means that these antiviral should be used in combination with other HIV-1 inhibitors. 


\section{Antiviral RNAi-Based Strategies}

RNAi has only recently been added to the list of nucleic acid-based therapeutics. In eukaryotic cells, RNAi plays an important role in the regulation of gene expression via microRNAs (miRNA). These are small noncoding RNAs that are expressed as primary miRNAs (pri-miRNAs) and processed by the cellular proteins Drosha and Dicer into mature miRNA of 21-25 nucleotides (Fig. 2). In mammals, miRNAs typically direct translational inhibition of cellular mRNAs bearing complementary sequences in the $3^{\prime}$ UTR (Grimson et al. 2007). RNAi has also been proposed to play a role in the cellular defense against viruses and silencing of transposable elements by generation of virus-specific siRNAs (Bennasser et al. 2005; Soifer et al. 2005; Triboulet et al. 2007; Yang and Kazazian 2006). Recently, it was shown that transposable elements in mouse oocytes are potently silenced by RNAi-related

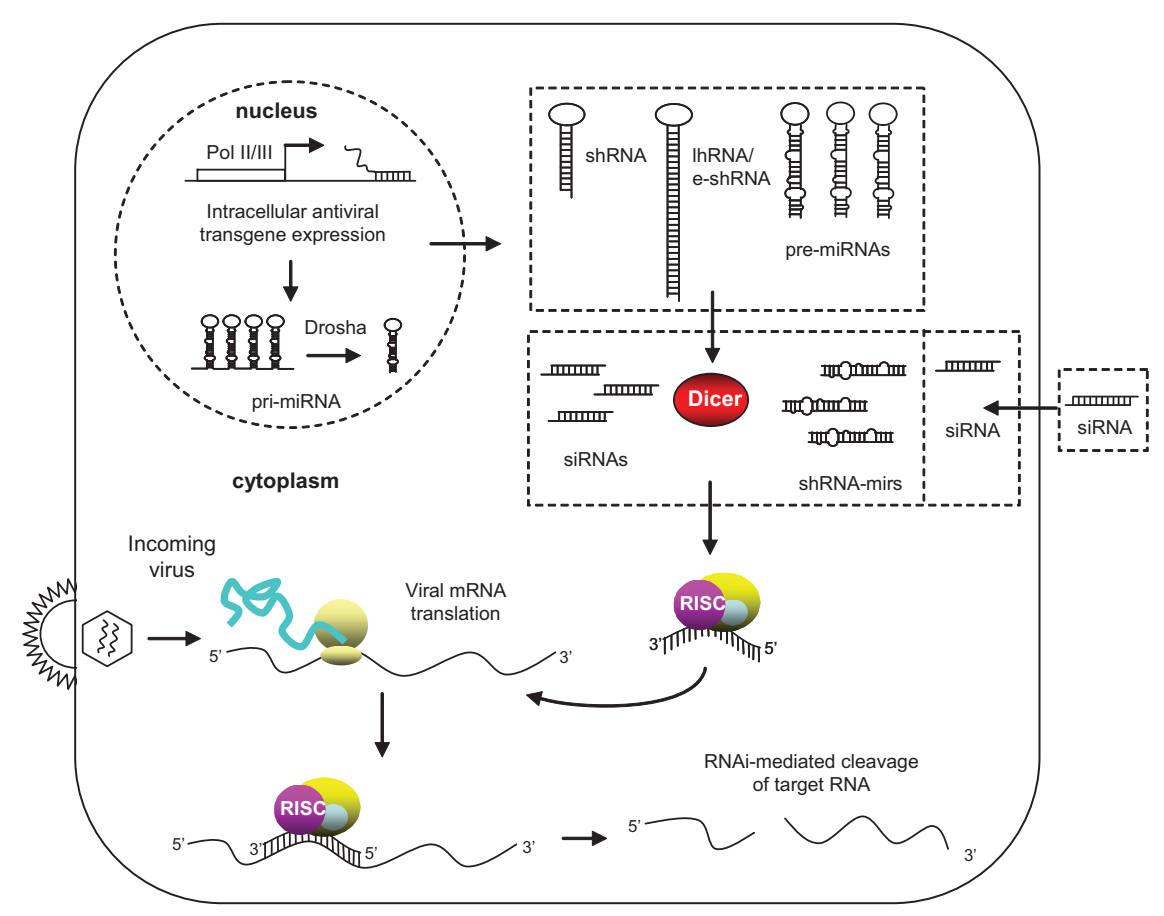

Fig. 2 RNAi inducers used in antiviral strategies. In general, RNAi is induced either by transfection of synthetic siRNAs into cells, or by stable or transient intracellular expression of doublestranded siRNA precursors (shRNA, e-shRNA, lhRNA, or pri-miRNAs). After transcription in the nucleus shRNAs, lhRNAs and e-shRNAs are exported to the cytoplasm and subsequently diced into mature siRNAs. Pri-miRNAs modified to encode antiviral siRNAs first undergo cleavage by Drosha before they are exported to the cytoplasm. Here the antiviral pre-miRNAs (also called shRNA-miRs) are processed by Dicer into the mature miRNAs. After loading of the antisense strand of the siRNAs/miRNAs into RISC, the complex will target and cleave viral transcripts bearing the complementary sequences 
mechanisms involving small RNAs (Tam et al. 2008; Watanabe et al. 2008). Both miRNAs and siRNAs are loaded into the RNA-induced silencing complex (RISC) and target RNAs for, respectively, translational repression or destruction (Fig. 2). Although the antiviral function of RNAi is well established in plants, insects, and nematodes, it is still debated whether RNAi has a similar role in mammals, but the circumstantial evidence is growing in support of this idea (Andersson et al. 2005; Bennasser et al. 2005; Cullen 2006; Grimson et al. 2007; Soifer et al. 2005; Tam et al. 2008; Voinnet 2005; Watanabe et al. 2006b, 2008; Yang and Kazazian 2006).

The discovery that exogenously delivered synthetic siRNA and intracellularly expressed short hairpin RNA (shRNA) trigger gene silencing in mammalian cells has made RNAi a powerful technique for generating genetic knock-downs (Brummelkamp et al. 2002; Elbashir et al. 2001). It also allowed the development of RNAi-based therapeutics for prevention of virus transmission or treatment of virus replication. An overview of therapeutic strategies used to induce antiviral RNAi responses is shown in Fig. 2. Synthetic siRNA duplexes used to induce RNAi are generally 21 nucleotides long with 2-nucleotide $3^{\prime}$ overhangs and are modeled after the natural Dicer cleavage products. Once the antisense strand (guide) of the antiviral siRNA is loaded into RISC, the complex will target the viral RNAs in a sequence-specific manner. Alternatively, transient transfection of plasmids that express antiviral shRNAs is also used to induce RNAi. These shRNAs are typically 19-29 base pairs long, with a small apical loop and a $3^{\prime}$-terminal UU overhang. The shRNAs are usually expressed in the nucleus under control of a polymerase III promoter (U6 or H1) and are translocated to the cytoplasm by Exportin-5. The shRNAs are processed in the cytoplasm by Dicer into functional siRNAs.

The technology of shRNA-induced RNAi has been significantly improved by using shRNA variants that more closely resemble natural miRNAs. This second generation shRNAs (shRNA-mirs) can be designed using the increased knowledge on the biochemistry of the RNAi mechanism and miRNA biogenesis. These shRNAmirs are expressed as larger transcripts under control of polymerase II promoters, and contain bulged nucleotides and internal loops as present in pri- and pre-miRNAs (Boden et al. 2004; Du et al. 2006; Liu et al. 2008; Silva et al. 2005). Compared to shRNAs, the shRNA-mirs show significantly increased activity.

Another possibility to induce RNAi is intracellular expression of long hairpin RNAs (lhRNAs) (Akashi et al. 2005; Konstantinova et al. 2006; Liu et al. 2007; Nishitsuji et al. 2006; Watanabe et al. 2006a; Weinberg et al. 2007). In contrast to transfection of dsRNA larger than $30 \mathrm{bp}$, intracellular expression does not seem to induce the interferon response. Efficient inhibition by lhRNAs has been reported for HIV-1, HCV, and HBV. Besides conventional lhRNAs, extended-shRNAs (e-shRNAs) have also been successfully used to trigger a potent RNAi response. These e-shRNAs encode individually effective siRNAs that are stacked to form a lhRNA structure (Liu et al. 2007). The potential advantage of a lhRNA or e-shRNA is the generation of multiple siRNAs from a single precursor molecule, which may prevent viral escape. 


\subsection{Chemically Modified siRNAs}

Similar to antisense oligonucleotides, synthetic siRNAs are relatively instable in vivo due to degradation by nuclease activity. The siRNA half life must be increased to be effective as antiviral therapeutic. This would allow treatment with infrequent administration of small amounts of siRNAs, which also increases the prophylactic potential of siRNAs. In case of influenza virus, individuals at risk could be treated with such stabilized antiviral siRNAs during the seasonal epidemic and thus avoid infection. Chemical modifications that were earlier used for antisense compounds have been successfully used to increase the half life of siRNAs in vivo while retaining their activity (Morrissey et al. 2005a, b; Rana 2007). For example, introducing a PS-linkage at the $3^{\prime}$ end renders siRNA resistant to $3^{\prime}$ exonuclease activity, whereas OMe modification gives resistance to endonucleases. However, some of the modifications that increase the stability have a negative effect on the siRNA activity (Czauderna et al. 2003). Modification of the $5^{\prime}$ end resulted in loss of siRNA activity, emphasizing its importance. Modifications in the antisense (passenger) strand can stabilize the siRNA, without a negative effect on the activity of the sense (guide) strand. LNA modification dramatically increases the potency of siRNA in vitro and in vivo without toxicity (Elmen et al. 2005).

\subsection{RNAi-Mediated Inhibition of HIV-1 and Virus Escape}

Numerous research groups have studied RNAi as an alternative method to block HIV-1, using both transient transfection of synthetic siRNAs and stably expressed shRNAs (Arrighi et al. 2004b; Das et al. 2004; Jacque et al. 2002; Lee et al. 2002; Martinez et al. 2002; Novina et al. 2002; Qin et al. 2003; Surabhi and Gaynor 2002; Ter Brake et al. 2006; Westerhout et al. 2006). Long-term virus suppression by an RNAi gene therapy approach is perhaps best suited to target HIV-1 and other viruses that cause a chronic infection. Lenti-, retro-, and adeno-associated virus (AAV) vectors can be used to stably transduce cells with constructs that express an antiviral shRNA, resulting in cellular resistance to the virus. Transduction of CD34 ${ }^{+}$ hematopoietic stem cells with anti-HIV-1 RNAi constructs ex vivo and grafting these cells back into the patient will result in a resistant cell population that might reconstitute the patients' immune system (Berkhout 2005; see also Chapter 11).

Prolonged in vitro culturing of resistant cells with HIV-1 resulted in the emergence of viral escape variants that are no longer targeted by the siRNAs. These RNAi escape variants contain point mutations or deletions within the siRNA target sequences (Das et al. 2004). In addition, an escape virus was described with a mutation outside the target sequence. This mutation triggered escape by inducing a conformational change in the local RNA secondary structure that rendered the target sequence inaccessible for RISC (Westerhout et al. 2005). Escape from RNAi has also been reported for poliovirus, hepatitis A virus, HBV, and HCV (Boden et al. 2003; Das et al. 2004; Gitlin et al. 2005; Kusov et al. 2006; Ter Brake and 
Berkhout 2005; von Eije et al. 2008; Westerhout et al. 2005; Wilson and Richardson 2005; Wu et al. 2005b). These combined results show that a single siRNA therapy is not sufficient to obtain long-term inhibition of virus replication. Escape from RNAi is reminiscent of the evolution of drug resistant HIV-1 variants in patients on antiretroviral therapy. Only the combined use of multiple HIV-1 drugs (highly active antiretroviral therapy or HAART) can permanently block virus replication without the emergence of resistant variants. Similarly, the combined expression of multiple siRNAs would be required to persistently block virus replication. This combinatorial approach should ideally target viral sequences that are essential and well conserved among different virus strains. The emergence of HIV-1 escape variants was delayed in cells expressing two siRNAs when compared to cells expressing a single siRNA (Ter Brake et al. 2006). In cells expressing four potent siRNAs, no viral escape was observed (Ter Brake et al. 2008).

lhRNAs have also been used to induce an anti-HIV-1 RNAi response (Barichievy et al. 2007; Konstantinova et al. 2006, 2007; Liu et al. 2007). These lhRNAs can be processed into multiple effective siRNAs, thus preventing the chance of viral escape. Although lhRNA have been shown to effectively inhibit HIV-1 replication, there is currently no data on their ability to prevent viral escape. The use of multiple siRNAs or lhRNAs should take into account the increased danger of side effects due to interference with cellular miRNA processing and function.

To prevent viral escape from RNAi, an alternative strategy is to target host factors that are essential for viral replication. However, there are few host factors that can be targeted without affecting host cell viability (Arrighi et al. 2004a; Liu et al. 2004; Ping et al. 2004; Qin et al. 2003; Zhou et al. 2004). For HIV-1, a well known example is the CCR5 coreceptor for HIV-1. This coreceptor is important for virus entry, yet mutation of the CCR5 gene does not affect the fitness of the host (Liu et al. 1996; Samson et al. 1996). Recently, Brass et al. (2008) published a large-scale siRNA screen to identify host factors required for HIV-1 replication (Brass et al. 2008). More than 250 HIV-dependency factors were identified, some of which may represent potential targets for therapy.

\subsection{RNAi-Based Strategies Against HBV}

Despite the availability of an effective HBV vaccine, the virus is still a major health problem with approximately 350 million persons infected worldwide. Hepatitis an infection of the liver that is caused by a variety of RNA viruses (hepatitis A virus, hepatitis B virus, hepatitis $\mathrm{C}$ virus). RNAi has been used to inhibit HBV replication both in vitro and in vivo (Carmona et al. 2006; Ely et al. 2008; Hamasaki et al. 2003; Klein et al. 2003; Konishi et al. 2003; Weinberg et al. 2007; Ying et al. 2003). $\mathrm{HBV}$ is a member of the Hepadnaviridae and its genome is a 3.2-kb double-stranded circular DNA. Synthetic siRNAs and shRNA expression constructs showed potent inhibition of HBV replication in mice (Chen et al. 2005, 2007; Giladi et al. 2003; McCaffrey et al. 2003; Morrissey et al. 2005b; Shin et al. 2006; Wu et al. 2005b; 
Xuan et al. 2006; Ying et al. 2007). The RNAi-based therapy needs to be provided for a long period because HBV causes a chronic infection of the liver. Transduction of the hepatocytes in vivo with a vector expressing anti-HBV shRNAs could provide such long-term protection. Chen et al. have indeed demonstrated long-term inhibition of HBV in mice transduced with an AAV vector to deliver the shRNA inhibitor. HBV DNA, mRNA, and protein levels were reduced in the liver of the transgenic mice, whereas the amount of circulating virus dropped by 2-3 logs. Virus inhibition was still apparent 120 days after vector administration (Chen et al. 2007). In addition, lhRNAs and shRNA-mirs could efficiently inhibit HBV replication in vitro and in mice (Ely et al. 2008; Weinberg et al. 2007).

\subsection{RNAi-Based Strategies Against Respiratory Viruses}

Respiratory viruses are perhaps best suited to target with RNAi-based therapeutics, because the upper airways and lungs are relatively easy to reach as target tissues. Already several studies reported therapeutic effects in animal models and in clinical trials. For example, siRNAs against influenza virus were found to reduce virus titers in the lungs of infected mice when siRNAs were administered through hydrodynamic intravenous injection (Ge et al. 2004). Similarly, virus titers were reduced when mice were given DNA vectors, either intravenously or intranasally, that express antiviral shRNAs (Ge et al. 2004). Moreover, reduced virus-induced mortality was scored in treated mice, even when the siRNA was delivered after virus infection, suggesting that siRNAs can act both in a prophylactic manner and in the treatment of established infections. In another study, synthetic siRNAs also protected mice against a lethal influenza virus challenge (Tompkins et al. 2004). This siRNA treatment induced a broad protection against the pathogenic avian influenza A viruses of serotypes $\mathrm{H} 5$ and $\mathrm{H} 7$.

Another respiratory virus for which RNAi therapeutics are being developed is respiratory syncytial virus (RSV). In fact, RSV was the first virus for which RNAimediated inhibition was demonstrated (Bitko and Barik 2001) and synthetic siRNAs are currently entering phase II clinical trials. RSV belongs to the paramyxoviridae and is an enveloped, nonsegmented, negative-strand RNA virus. RSV is a major cause of respiratory illness in both the upper and lower respiratory tract, typically leading to common cold-like symptoms that in some cases - especially in young children - lead to more serious illness such as bronchiolitis and pneumonia. In mice, replication of RSV and also human parainfluenza virus could be blocked by synthetic siRNAs (Bitko et al. 2005). Synthetic siRNAs and intranasal administration of plasmids expressing shRNAs resulted in a significant decrease of the RSV load (Zhang et al. 2005). Similar to siRNA-induced inhibition of influenza virus, the siRNAs against RSV were effective both before and after infection with RSV. Alnylam has presented the results of a phase I clinical trial with its leading siRNA drug candidate ALN-RSV01 (http://www.alnylam.com/). The drug was found to be safe and well tolerated when administered intranasally in two phase I clinical studies 
(DeVincenzo et al. 2008). Phase II clinical trials in naturally infected RSV patients were initiated in April 2008. ALN-RSV01 is expected to advance into the pediatric patient population by the second half of 2008 .

RNAi against the severe acute respiratory syndrome coronavirus (SARScoronavirus) and other coronaviruses has also been studied extensively. Both siRNAs and plasmid-derived shRNAs were effective in blocking virus replication in cell culture infections (He et al. 2003; Lu et al. 2004; Ni et al. 2005; Pyrc et al. 2006; Wang et al. 2004; Wu et al. 2005a; Zhang et al. 2004). Potent siRNA inhibitors against the SARS-coronavirus spike and pol mRNAs were also tested for efficacy and safety in a rhesus macaque SARS model. The siRNAs were administered intranasally as prophylactic, concurrent with viral challenge, or early post-exposure ( $\mathrm{Li}$ et al. 2005a). Similar to the mice studies with anti-influenza siRNAs and anti-RSV siRNAs, both prophylactic and therapeutic effects were observed. siRNA treatment caused a significant reduction in viral RNA levels, SARS-like symptoms, and lung histopathology. These combined findings suggest that low dosages of inhaled or intravenously administered siRNAs or shRNA plasmids may provide an easy and efficient basis for prophylaxis against respiratory viruses in certain situations - for example, a pandemic influenza threat - or antiviral therapy of already infected individuals.

\subsection{RNAi Side Effects and Off-Target Effects}

RNAi is a highly specific tool for inducing gene knock-down. However, studies show that high expression of siRNA/shRNAs can induce interferon responses and other unwanted side effects (Bridge et al. 2003; Jackson and Linsley 2004). Cellular transcripts containing partial complementarity with an siRNA can also be targeted for RNAi-mediated knock-down (Birmingham et al. 2006; Fedorov et al. 2006; Jackson et al. 2003). These off-target effects are of great concern in the development of safe RNAi-based antivirals, because they will have an impact on cell viability (Fedorov et al. 2006; Jackson and Linsley 2004). High concentrations of siRNA/shRNAs may also interfere with cellular miRNA processing and function. This problem is caused by the fact that shRNA processing uses the cellular pathway for miRNA processing. In particular, Exportin-5, which is required for nuclear export and stability of miRNAs, was found to be a limiting factor in the RNAi pathway that could be saturated by exogenous shRNAs. In extreme cases, such side effects can have severe consequences, as illustrated by the mice that died after treatment with an AAV vector for overexpression of shRNAs in the liver (Grimm et al. 2006). This study also showed that there is an shRNA-threshold for toxicity. Because of our limited knowledge on cellular miRNA function, we should not underestimate the impact of shRNAs on these processes. Moderate expression of highly active shRNAs is essential for the development of safe RNAi therapeutics, and candidate shRNA/siRNA inhibitors should be screened for off-target effects. Inducible promoters are useful to regulate shRNA expression to avoid off-target effects. To avoid 
toxic off-target effects of antiviral RNAi therapeutics, viruses should ideally be targeted transiently, locally, and with a low dosage. This could be realized for acute respiratory viral infections, but treatment of chronic viral infections may require a durable gene therapy approach. An elegant strategy to reduce potential off-target effects of the siRNA passenger strand is the use of so-called small internally segmented interfering RNAs (sisiRNA) (Bramsen et al. 2007). These sisiRNAs are composed of an intact antisense strand complemented with two shorter 10-12 nt sense strands. Because of its segmented nature the passenger strand is inactive, whereas the antisense strand can still efficiently induce a potent RNAi response.

Delivery of the siRNAs to the right target cells will also limit the impact of potential off-target effects. Progress has been made by using nanoparticles loaded with siRNAs. These particles, ranging between $25-40 \mathrm{~nm}$ in diameter, can be used to load high concentrations of siRNAs into a protected environment. The nanoparticles can be targeted to specific cells or tissues by decorating their surface with ligands that target specific cell surface receptors. Ligands such as transferrin, Her2 antibodies, folate, and integrin-targeting peptide have already been successfully used to target siRNA particles to cells bearing the corresponding receptors (Guo et al. 2006; Hu-Lieskovan et al. 2005; Schiffelers et al. 2004; Tan et al. 2007). These results are promising and will contribute to the further development of safe and efficient siRNA delivery systems.

\section{Conclusions}

The development of nucleic acid-based therapeutics is not as straightforward as researchers had initially anticipated. Stability, toxicity, specificity, and delivery of the compounds continue to be challenging issues that need further optimization. In recent years, researchers have come up with intricate solutions that have greatly improved the efficacy of potential antisense, ribozyme, as well as RNAi-based therapeutics. Clinical trials for all these types of nucleic acid-based therapeutics are underway. So far, data from several trials and studies in animal models look promising, in particular, the therapies that trigger the RNAi pathway. However, history has shown that compounds that do well in phase I or phase II clinical trials may still fail in phase III. A striking example is the nonspecific suppression of angiogenesis by siRNA via toll-like receptor 3 (Kleinman et al. 2008). It will become clear in the near future which compounds will make it as a new class of antiviral therapeutics.

Acknowledgements We thank Truus Abbink for critical reading of the manuscript. RNAi research in the Berkhout lab is sponsored by ZonMw (Vici grant and Translational Gene Therapy program), NWO-CW (Top grant), the European Union (LSHP-CT-2006-037301), and the Technology Foundation STW (grant AGT.7708). 


\section{References}

Akashi H, Miyagishi M, Yokota T, Watanabe H, Hino T, Nishina K, Kohara M, Taira K (2005) Escape from the interferon response associated with RNA interference using vectors that encode long modified hairpin-RNA. Molecular BioSystems 1:382-390

Anderson J, Li MJ, Palmer B, Remling L, Li S, Yam P, Yee JK, Rossi J, Zaia J, Akkina R (2007) Safety and efficacy of a lentiviral vector containing three anti-HIV genes-CCR5 ribozyme, Tatrev siRNA, and TAR decoy-in SCID-hu mouse-derived T Cells. Mol Ther 5:1182-1188

Andersson MG, Haasnoot PCJ, Xu N, Berenjian S, Berkhout B, Akusjarvi G (2005) Suppression of RNA interference by adenovirus virus-associated RNA. J Virol 79:9556-9565

Arrighi JF, Pion M, Garcia E, Escola JM, van Kooyk Y, Geijtenbeek TB, Piguet V (2004a) DCSIGN-mediated infectious synapse formation enhances X4 HIV-1 transmission from dendritic cells to T cells. J Exp Med 200:1279-1288

Arrighi JF, Pion M, Wiznerowicz M, Geijtenbeek TB, Garcia E, Abraham S, Leuba F, Dutoit V, Ducrey-Rundquist O, van Kooyk Y, Trono D, Piguet V (2004b) Lentivirus-mediated RNA interference of DC-SIGN expression inhibits human immunodeficiency virus transmission from dendritic cells to T cells. J Virol 78:10848-10855

Bahner I, Kearns K, Hao QL, Smogorzewska EM, Kohn DB (1996) Transduction of human CD34+ hematopoietic progenitor cells by a retroviral vector expressing an RRE decoy inhibits human immunodeficiency virus type 1 replication in myelomonocytic cells produced in long-term culture. J Virol 70:4352-4360

Barichievy S, Saayman S, von Eije KJ, Morris KV, Arbuthnot P, Weinberg MS (2007) The inhibitory efficacy of RNA POL III-expressed long hairpin RNAs targeted to untranslated regions of the HIV-1 5' long terminal repeat. Oligonucleotides 17:419-431

Bellecave P, Andreola ML, Ventura M, Tarrago-Litvak L, Litvak S, Astier-Gin T (2003) Selection of DNA aptamers that bind the RNA-dependent RNA polymerase of hepatitis $\mathrm{C}$ virus and inhibit viral RNA synthesis in vitro. Oligonucleotides 13:455-463

Bennasser Y, Le SY, Benkirane M, Jeang KT (2005) Evidence that HIV-1 encodes an siRNA and a suppressor of RNA silencing. Immunity 22:607-619

Berkhout B (2005) RNA interference as an antiviral approach: targeting HIV-1 Curr Opin Mol Ther 6:141-145

Birmingham A, Anderson EM, Reynolds A, Ilsley-Tyree D, Leake D, Fedorov Y, Baskerville S, Maksimova E, Robinson K, Karpilow J, Marshall WS, Khvorova A (2006) 3' UTR seed matches, but not overall identity, are associated with RNAi off-targets. Nat Methods 3:199-204

Bitko V, Barik S (2001) Phenotypic silencing of cytoplasmic genes using sequence-specific doublestranded short interfering RNA and its application in the reverse genetics of wild type negativestrand RNA viruses. BMC Microbiol 1:34

Bitko V, Musiyenko A, Shulyayeva O, Barik S (2005) Inhibition of respiratory viruses by nasally administered siRNA. Nat Med 11:50-55

Boden D, Pusch O, Lee F, Tucker L, Ramratnam B (2003) Human immunodeficiency virus type 1 escape from RNA interference. J Virol 77:11531-11535

Boden D, Pusch O, Silbermann R, Lee F, Tucker L, Ramratnam B (2004) Enhanced gene silencing of HIV-1 specific siRNA using microRNA designed hairpins. Nucleic Acids Res 32:1154-1158

Bramsen JB, Laursen MB, Damgaard CK, Lena SW, Babu BR, Wengel J, Kjems J (2007) Improved silencing properties using small internally segmented interfering RNAs. Nucleic Acids Res 35:5886-5897

Brass AL, Dykxhoorn DM, Benita Y, Yan N, Engelman A, Xavier RJ, Lieberman J, Elledge SJ (2008) Identification of host proteins required for HIV infection through a functional genomic screen. Science 319:921-926

Bridge AJ, Pebernard S, Ducraux A, Nicoulaz AL, Iggo R (2003) Induction of an interferon response by RNAi vectors in mammalian cells. Nat Genet 34:263-264

Brummelkamp TR, Bernards R, Agami R (2002) A system for stable expression of short interfering RNAs in mammalian cells. Science 296:550-553 
Burke DH, Scates L, Andrews K, Gold L (1996) Bent pseudoknots and novel RNA inhibitors of type 1 human immunodeficiency virus (HIV-1) reverse transcriptase. J Mol Biol 264:650-666

Burrer R, Neuman BW, Ting JP, Stein DA, Moulton HM, Iversen PL, Kuhn P, Buchmeier MJ (2007) Antiviral effects of antisense morpholino oligomers in murine coronavirus infection models. J Virol 81:5637-5648

Carmona S, Ely A, Crowther C, Moolla N, Salazar FH, Marion PL, Ferry N, Weinberg MS, Arbuthnot P (2006) Effective inhibition of HBV replication in vivo by anti-HBx short hairpin RNAs. Mol Ther 13:411-421

Chen CC, Ko TM, Ma HI, Wu HL, Xiao X, Li J, Chang CM, Wu PY, Chen CH, Han JM, Yu CP, Jeng KS, Hu CP, Tao MH (2007) Long-term inhibition of hepatitis B virus in transgenic mice by double-stranded adeno-associated virus 8-delivered short hairpin RNA. Gene Ther 14:11-19

Cheng TL, Chang WW, Su IJ, Lai MD, Huang W, Lei HY, Chang WT (2005) Therapeutic inhibition of hepatitis B virus surface antigen expression by RNA interference. Biochem Biophys Res Commun 336:820-830

Cullen BR (2006) Is RNA interference involved in intrinsic antiviral immunity in mammals? Nat Immunol 7:563-567

Czauderna F, Fechtner M, Dames S, Aygun H, Klippel A, Pronk GJ, Giese K, Kaufmann J (2003) Structural variations and stabilising modifications of synthetic siRNAs in mammalian cells. Nucleic Acids Res 31:2705-2716

Das AT, Brummelkamp TR, Westerhout EM, Vink M, Madiredjo M, Bernards R, Berkhout B (2004) Human immunodeficiency virus type 1 escapes from RNA interference-mediated inhibition. J Virol 78:2601-2605

DeVincenzo J, Cehelsky JE, Alvarez R, Elbashir S, Harborth J, Toudjarska I, Nechev L, Murugaiah V, Van Vliet A, Vaishnaw AK, Meyers R (2008) Evaluation of the safety, tolerability and pharmacokinetics of ALN-RSV01, a novel RNAi antiviral therapeutic directed against respiratory syncytial virus (RSV). Antiviral Res 77:225-231

Du G, Yonekubo J, Zeng Y, Osisami M, Frohman MA (2006) Design of expression vectors for RNA interference based on miRNAs and RNA splicing. FEBS J 273:5421-5427

Elbashir SM, Harborth J, Lendeckel W, Yalcin A, Weber K, Tuschl T (2001) Duplexes of 21nucleotide RNAs mediate RNA interference in cultured mammalian cells. Nature 411:494-498

Elmen J, Thonberg H, Ljungberg K, Frieden M, Westergaard M, Xu Y, Wahren B, Liang Z, Orum H, Koch T, Wahlestedt C (2005) Locked nucleic acid (LNA) mediated improvements in siRNA stability and functionality. Nucleic Acids Res 33:439-447

Ely A, Naidoo T, Mufamadi S, Crowther C, Arbuthnot P (2008) Expressed anti-HBV primary microRNA shuttles inhibit viral replication efficiently in vitro and in vivo. Mol Ther 16:11051112

Fedorov Y, Anderson EM, Birmingham A, Reynolds A, Karpilow J, Robinson K, Leake D, Marshall WS, Khvorova A (2006) Off-target effects by siRNA can induce toxic phenotype. RNA 12:1188-1196

Ge Q, Filip L, Bai A, Nguyen T, Eisen HN, Chen J (2004) Inhibition of influenza virus production in virus-infected mice by RNA interference. Proc Natl Acad Sci USA 101:8676-8681

Giladi H, Ketzinel-Gilad M, Rivkin L, Felig Y, Nussbaum O, Galun E (2003) Small interfering RNA inhibits hepatitis B virus replication in mice. Mol Ther 8:769-776

Gitlin L, Stone JK, Andino R (2005) Poliovirus escape from RNA interference: short interfering RNA-target recognition and implications for therapeutic approaches. J Virol 79:1027-1035

Gonzalez-Carmona MA, Schussler S, Serwe M, Alt M, Ludwig J, Sproat BS, Steigerwald R, Hoffmann P, Quasdorff M, Schildgen O, Caselmann WH (2006) Hammerhead ribozymes with cleavage site specificity for $\mathrm{NUH}$ and $\mathrm{NCH}$ display significant anti-hepatitis $\mathrm{C}$ viral effect in vitro and in recombinant HepG2 and CCL13 cells. J Hepatol 44:1017-1025

Grimm D, Streetz KL, Jopling CL, Storm TA, Pandey K, Davis CR, Marion P, Salazar F, Kay MA (2006) Fatality in mice due to oversaturation of cellular microRNA/short hairpin RNA pathways. Nature 441:537-541

Grimson A, Farh KK, Johnston WK, Garrett-Engele P, Lim LP, Bartel DP (2007) MicroRNA targeting specificity in mammals: determinants beyond seed pairing. Mol Cell 27:91-105 
Gu S, Ji J, Kim JD, Yee JK, Rossi JJ (2006) Inhibition of infectious human immunodeficiency virus type 1 virions via lentiviral vector encoded short antisense RNAs. Oligonucleotides 16:287-295

Guo S, Huang F, Guo P (2006) Construction of folate-conjugated pRNA of bacteriophage phi29 DNA packaging motor for delivery of chimeric siRNA to nasopharyngeal carcinoma cells. Gene Ther 13:814-820

Haasnoot J, Westerhout EM, Berkhout B (2007) RNA interference against viruses: strike and counterstrike. Nat Biotechnol 25:1435-1443

Hamasaki K, Nakao K, Matsumoto K, Ichikawa T, Ishikawa H, Eguchi K (2003) Short interfering RNA-directed inhibition of hepatitis B virus replication. FEBS Lett 543:51-54

He ML, Zheng B, Peng Y, Peiris JS, Poon LL, Yuen KY, Lin MC, Kung HF, Guan Y (2003) Inhibition of SARS-associated coronavirus infection and replication by RNA interference. JAMA 290:2665-2666

Held DM, Kissel JD, Thacker SJ, Michalowski D, Saran D, Ji J, Hardy RW, Rossi JJ, Burke DH (2007) Cross-clade inhibition of recombinant HIV-1, HIV-2 and SIVcpz reverse transcriptases by RNA pseudoknot aptamers. J Virol 81:5375-5384

Hu-Lieskovan S, Heidel JD, Bartlett DW, Davis ME, Triche TJ (2005) Sequence-specific knockdown of EWS-FLI1 by targeted, nonviral delivery of small interfering RNA inhibits tumor growth in a murine model of metastatic Ewing's sarcoma. Cancer Res 65:8984-8992

Iversen PL (2001) Phosphorodiamidate morpholino oligomers: favorable properties for sequencespecific gene inactivation. Curr Opin Mol Ther 3:235-238

Jackson AL, Linsley PS (2004) Noise amidst the silence: off-target effects of siRNAs? Trends Genet 20:521-524

Jackson AL, Bartz SR, Schelter J, Kobayashi SV, Burchard J, Mao M, Li B, Cavet G, Linsley PS (2003) Expression profiling reveals off-target gene regulation by RNAi. Nat Biotechnol 21:635-637

Jacque JM, Triques K, Stevenson M (2002) Modulation of HIV-1 replication by RNA interference. Nature 418:435-438

Jakobsen MR, Haasnoot J, Wengel J, Berkhout B, Kjems J (2007) Efficient inhibition of HIV-1 expression by LNA modified antisense oligonucleotides and DNAzymes targeted to functionally selected binding sites. Retrovirology 4:29

James W (2007) Aptamers in the virologists' toolkit. J Gen Virol 88:351-364

Klein C, Bock CT, Wedemeyer H, Wustefeld T, Locarnini S, Dienes HP, Kubicka S, Manns MP, Trautwein C (2003) Inhibition of hepatitis B virus replication in vivo by nucleoside analogues and siRNA. Gastroenterology 125:9-18

Kleinman ME, Yamada K, Takeda A, Chandrasekaran V, Nozaki M, Baffi JZ, Albuquerque RJ, Yamasaki S, Itaya M, Pan Y, Appukuttan B, Gibbs D, Yang Z, Kariko K, Ambati BK, Wilgus TA, DiPietro LA, Sakurai E, Zhang K, Smith JR, Taylor EW, Ambati J (2008) Sequence- and target-independent angiogenesis suppression by siRNA via TLR3. Nature 452:591-597

Kohn DB, Bauer G, Rice CR, Rothschild JC, Carbonaro DA, Valdez P, Hao Q, Zhou C, Bahner I, Kearns K, Brody K, Fox S, Haden E, Wilson K, Salata C, Dolan C, Wetter C, Aguilar-Cordova E, Church J (1999) A clinical trial of retroviral-mediated transfer of a rev-responsive element decoy gene into $\mathrm{CD} 34(+)$ cells from the bone marrow of human immunodeficiency virus-1-infected children. Blood 94:368-371

Konishi M, Wu CH, Wu GY (2003) Inhibition of HBV replication by siRNA in a stable HBVproducing cell line. Hepatology 38:842-850

Konstantinova P, de Vries W, Haasnoot J, Ter Brake O, de Haan P, Berkhout B (2006) Inhibition of human immunodeficiency virus type 1 by RNA interference using long-hairpin RNA. Gene Ther 13:1403-1413

Konstantinova P, Ter Brake O, Haasnoot J, de Haan P, Berkhout B (2007) Trans-inhibition of HIV-1 by a long hairpin RNA expressed within the viral genome. Retrovirology 4:15

Kusov Y, Kanda T, Palmenberg A, Sgro JY, Gauss-Muller V (2006) Silencing of hepatitis A virus infection by small interfering RNAs. J Virol 80:5599-5610

Larsen HJ, Bentin T, Nielsen PE (1999) Antisense properties of peptide nucleic acid. Biochim Biophys Acta 1489:159-166 
Lee NS, Dohjima T, Bauer G, Li H, Li MJ, Ehsani A, Salvaterra P, Rossi J (2002) Expression of small interfering RNAs targeted against HIV-1 rev transcripts in human cells. Nat Biotechnol 20:500-505

Levine BL, Humeau LM, Boyer J, MacGregor RR, Rebello T, Lu X, Binder GK, Slepushkin V, Lemiale F, Mascola JR, Bushman FD, Dropulic B, June CH (2006) Gene transfer in humans using a conditionally replicating lentiviral vector. Proc Natl Acad Sci USA 103:17372-17377

Li BJ, Tang Q, Cheng D, Qin C, Xie FY, Wei Q, Xu J, Liu Y, Zheng BJ, Woodle MC, Zhong N, Lu PY (2005a) Using siRNA in prophylactic and therapeutic regimens against SARS coronavirus in Rhesus macaque. Nat Med 11:944-951

Li MJ, Bauer G, Michienzi A, Yee JK, Lee NS, Kim J, Li S, Castanotto D, Zaia J, Rossi JJ (2003) Inhibition of HIV-1 infection by lentiviral vectors expressing Pol III-promoted anti-HIV RNAs. Mol Ther 8:196-206

Li MJ, Kim J, Li S, Zaia J, Yee JK, Anderson J, Akkina R, Rossi JJ (2005b) Long-term inhibition of HIV-1 infection in primary hematopoietic cells by lentiviral vector delivery of a triple combination of anti-HIV shRNA, anti-CCR5 ribozyme, and a nucleolar-localizing TAR decoy. Mol Ther 12:900-909

Liu R, Paxton WA, Choe S, Ceradini D, Martin SR, Horuk R, MacDonald ME, Stuhlmann H, Koup RA, Landau NR (1996) Homozygous defect in HIV-1 coreceptor accounts for resistance of some multiply-exposed individuals to HIV-1 infection. Cell 86:367-377

Liu S, Asparuhova M, Brondani V, Ziekau I, Klimkait T, Schumperli D (2004) Inhibition of HIV-1 multiplication by antisense U7 snRNAs and siRNAs targeting cyclophilin A. Nucleic Acids Res 32:3752-3759

Liu YP, Haasnoot J, Berkhout B (2007) Design of extended short hairpin RNAs for HIV-1 inhibition. Nucleic Acids Res 35:5683-5693

Liu YP, Haasnoot J, Ter Brake O, Berkhout B, Konstantinova P (2008) Inhibition of HIV-1 by multiple siRNAs expressed from a single microRNA polycistron. Nucleic Acids Res 36:28112824

Lu A, Zhang H, Zhang X, Wang H, Hu Q, Shen L, Schaffhausen BS, Hou W, Li L (2004) Attenuation of SARS coronavirus by a short hairpin RNA expression plasmid targeting RNA-dependent RNA polymerase. Virol 324:84-89

Macpherson JL, Boyd MP, Arndt AJ, Todd AV, Fanning GC, Ely JA, Elliott F, Knop A, Raponi M, Murray J, Gerlach W, Sun LQ, Penny R, Symonds GP, Carr A, Cooper DA (2005) Long-term survival and concomitant gene expression of ribozyme-transduced CD4 + T-lymphocytes in HIV-infected patients. J Gene Med 7:552-564

Martinez MA, Gutierrez A, Armand-Ugon M, Blanco J, Parera M, Gomez J, Clotet B, Este JA (2002) Suppression of chemokine receptor expression by RNA interference allows for inhibition of HIV-1 replication. AIDS 16:2385-2390

McCaffrey AP, Nakai H, Pandey K, Huang Z, Salazar FH, Xu H, Wieland SF, Marion PL, Kay MA (2003) Inhibition of hepatitis B virus in mice by RNA interference. Nat Biotechnol 21:639-644

McHutchison JG, Patel K, Pockros P, Nyberg L, Pianko S, Yu RZ, Dorr FA, Kwoh TJ (2006) A phase I trial of an antisense inhibitor of hepatitis C virus (ISIS 14803), administered to chronic hepatitis C patients. J Hepatol 44:88-96

Monia BP, Lesnik EA, Gonzalez C, Lima WF, McGee D, Guinosso CJ, Kawasaki AM, Cook PD, Freier SM (1993) Evaluation of 2'-modified oligonucleotides containing $2^{\prime}$-deoxy gaps as antisense inhibitors of gene expression. J Biol Chem 268:14514-14522

Morrissey DV, Blanchard K, Shaw L, Jensen K, Lockridge JA, Dickinson B, McSwiggen JA, Vargeese C, Bowman K, Shaffer CS, Polisky BA, Zinnen S (2005a) Activity of stabilized short interfering RNA in a mouse model of hepatitis B virus replication. Hepatology 41:1349-1356

Morrissey DV, Lockridge JA, Shaw L, Blanchard K, Jensen K, Breen W, Hartsough K, Machemer L, Radka S, Jadhav V, Vaish N, Zinnen S, Vargeese C, Bowman K, Shaffer CS, Jeffs LB, Judge A, Maclachlan I, Polisky B (2005b) Potent and persistent in vivo anti-HBV activity of chemically modified siRNAs. Nat Biotechnol 23:1002-1007 
Ni B, Shi X, Li Y, Gao W, Wang X, Wu Y (2005) Inhibition of replication and infection of severe acute respiratory syndrome-associated coronavirus with plasmid-mediated interference RNA. Antivir Ther 10:527-533

Nishitsuji H, Kohara M, Kannagi M, Masuda T (2006) Effective suppression of human immunodeficiency virus type 1 through a combination of short- or long-hairpin RNAs targeting essential sequences for retroviral integration. J Virol 80:7658-7666

Novina CD, Murray MF, Dykxhoorn DM, Beresford PJ, Riess J, Lee SK, Collman RG, Lieberman J, Shankar P, Sharp PA (2002) siRNA-directed inhibition of HIV-1 infection. Nat Med 8:681-686

Peracchi A (2004) Prospects for antiviral ribozymes and deoxyribozymes. Rev Med Virol 14:47-64

Petersen M, Wengel J (2003) LNA: a versatile tool for therapeutics and genomics. Trends Biotechnol 21:74-81

Ping YH, Chu CY, Cao H, Jacque JM, Stevenson M, Rana TM (2004) Modulating HIV-1 replication by RNA interference directed against human transcription elongation factor SPT5. Retrovirology $1: 46$

Pyrc K, Bosch BJ, Berkhout B, Jebbink MF, Dijkman R, Rottier P, van der Hoek L (2006) Inhibition of HCoV-NL63 infection at early stages of the replication cycle. Antim Ag Chemoth 50:2000-2008

Qin XF, An DS, Chen ISY, Baltimore D (2003) Inhibiting HIV-1 infection in human T cells by lentiviral-mediated delivery of small interfering RNA against CCR5. Proc Natl Acad Sci USA 100:183-188

Rana TM (2007) Illuminating the silence: understanding the structure and function of small RNAs. Nat Rev Mol Cell Biol 8:23-36

Samson M, Libert F, Doranz BJ, Rucker J, Liesnard C, Farber C-M, Saragosti S, Lapoumeroulie C, Cognaux J, Forceille C, Muyldermans G, Verhofstede C, Burtonboy G, Georges M, Imai T, Rana S, Yi Y, Smyth RJ, Collman RG, Doms RW, Vassart G, Parmentier M (1996) Resistance to HIV-1 infection in caucasian individuals bearing mutant alleles of the CCR-5 chemokine receptor gene. Nature 382:722-725

Santoro SW, Joyce GF (1997) A general purpose RNA-cleaving DNA enzyme. Proc Natl Acad Sci USA 94:4262-4266

Schiffelers RM, Ansari A, Xu J, Zhou Q, Tang Q, Storm G, Molema G, Lu PY, Scaria PV, Woodle MC (2004) Cancer siRNA therapy by tumor selective delivery with ligand-targeted sterically stabilized nanoparticle. Nucleic Acids Res 32:e149

Shin D, Kim SI, Kim M, Park M (2006) Efficient inhibition of hepatitis B virus replication by small interfering RNAs targeted to the viral X gene in mice. Virus Res 119:146-153

Silva JM, Li MZ, Chang K, Ge W, Golding MC, Rickles RJ, Siolas D, Hu G, Paddison PJ, Schlabach MR, Sheth N, Bradshaw J, Burchard J, Kulkarni A, Cavet G, Sachidanandam R, McCombie WR, Cleary MA, Elledge SJ, Hannon GJ (2005) Second-generation shRNA libraries covering the mouse and human genomes. Nat Genet 37:1281-1288

Soifer HS, Zaragoza A, Peyvan M, Behlke MA, Rossi JJ (2005) A potential role for RNA interference in controlling the activity of the human LINE-1 retrotransposon. Nucleic Acids Res 33:846-856

Stein D, Foster E, Huang SB, Weller D, Summerton J (1997) A specificity comparison of four antisense types: morpholino, 2'-O-methyl RNA, DNA, and phosphorothioate DNA. Antisense Nucleic Acid Drug Dev 7:151-157

Surabhi RM, Gaynor RB (2002) RNA interference directed against viral and cellular targets inhibits human immunodeficiency virus type 1 replication. J Virol 76:12963-12973

Swayze EE, Siwkowski AM, Wancewicz EV, Migawa MT, Wyrzykiewicz TK, Hung G, Monia BP, Bennett CF (2007) Antisense oligonucleotides containing locked nucleic acid improve potency but cause significant hepatotoxicity in animals. Nucleic Acids Res 35:687-700

Tam OH, Aravin AA, Stein P, Girard A, Murchison EP, Cheloufi S, Hodges E, Anger M, Sachidanandam R, Schultz RM, Hannon GJ (2008) Pseudogene-derived small interfering RNAs regulate gene expression in mouse oocytes. Nature 453:534-538 
Tan WB, Jiang S, Zhang Y (2007) Quantum-dot based nanoparticles for targeted silencing of HER2/neu gene via RNA interference. Biomaterials 28:1565-1571

Ter Brake O, Berkhout B (2005) A novel approach for inhibition of HIV-1 by RNA interference: counteracting viral escape with a second generation of siRNAs. J RNAi Gene Silencing $1(2): 56-65$

Ter Brake O, Konstantinova P, Ceylan M, Berkhout B (2006) Silencing of HIV-1 with RNA interference: a multiple shRNA approach. Mol Ther 14:883-892

Ter Brake O, 't Hooft K, Liu YP, Centlivre M, von Eije KJ, Berkhout B (2008) Lentiviral vector design for multiple shRNA expression and durable HIV-1 inhibition. Mol Ther 16:557-564

Tompkins SM, Lo CY, Tumpey TM, Epstein SL (2004) Protection against lethal influenza virus challenge by RNA interference in vivo. Proc Natl Acad Sci USA 101:8682-8686

Triboulet R, Mari B, Lin YL, Chable-Bessia C, Bennasser Y, Lebrigand K, Cardinaud B, Maurin T, Barbry P, Baillat V, Reynes J, Corbeau P, Jeang KT, Benkirane M (2007) Suppression of microRNA-silencing pathway by HIV-1 during virus replication. Science 315:1579-1582

Tuerk C, MacDougal S, Gold L (1992) RNA pseudoknots that inhibit human immunodeficiency virus type 1 reverse transcriptase. Proc Natl Acad Sci USA 89:6988-6992

Turner JJ, Fabani M, Arzumanov AA, Ivanova G, Gait MJ (2006) Targeting the HIV-1 RNA leader sequence with synthetic oligonucleotides and siRNA: chemistry and cell delivery. Biochim Biophys Acta 1758:290-300

Van Aerschot A (2006) Oligonucleotides as antivirals: dream or realistic perspective? Antiviral Res 71:307-316

Vitravene Study Group (2002) A randomized controlled clinical trial of intravitreous fomivirsen for treatment of newly diagnosed peripheral cytomegalovirus retinitis in patients with AIDS. Am J Ophthalmol 133:467-474

Voinnet O (2005) Induction and suppression of RNA silencing: insights from viral infections. Nat Rev Genet 6:206-220

von Eije KJ, Ter Brake O, Berkhout B (2008) Human immunodeficiency virus type 1 escape is restricted when conserved genome sequences are targeted by RNA interference. J Virol 82:28952903

Wahlestedt C, Salmi P, Good L, Kela J, Johnsson T, Hokfelt T, Broberger C, Porreca F, Lai J, Ren K, Ossipov M, Koshkin A, Jakobsen N, Skouv J, Oerum H, Jacobsen MH, Wengel J (2000) Potent and nontoxic antisense oligonucleotides containing locked nucleic acids. Proc Natl Acad Sci USA 97:5633-5638

Wang Z, Ren L, Zhao X, Hung T, Meng A, Wang J, Chen YG (2004) Inhibition of severe acute respiratory syndrome virus replication by small interfering RNAs in mammalian cells. J Virol 78:7523-7527

Warfield KL, Swenson DL, Olinger GG, Nichols DK, Pratt WD, Blouch R, Stein DA, Aman MJ, Iversen PL, Bavari S (2006) Gene-specific countermeasures against Ebola virus based on antisense phosphorodiamidate morpholino oligomers. PLoS Pathog 2:e1

Watanabe T, Sudoh M, Miyagishi M, Akashi H, Arai M, Inoue K, Taira K, Yoshiba M, Kohara M (2006a) Intracellular-diced dsRNA has enhanced efficacy for silencing HCV RNA and overcomes variation in the viral genotype. Gene Ther 883-892

Watanabe T, Takeda A, Tsukiyama T, Mise K, Okuno T, Sasaki H, Minami N, Imai H (2006b) Identification and characterization of two novel classes of small RNAs in the mouse germline: retrotransposon-derived siRNAs in oocytes and germline small RNAs in testes. Genes Dev 20:1732-1743

Watanabe T, Totoki Y, Toyoda A, Kaneda M, Kuramochi-Miyagawa S, Obata Y, Chiba H, Kohara Y, Kono T, Nakano T, Surani MA, Sakaki Y, Sasaki H (2008) Endogenous siRNAs from naturally formed dsRNAs regulate transcripts in mouse oocytes. Nature 453:539-543

Weinberg MS, Ely A, Barichievy S, Crowther C, Mufamadi S, Carmona S, Arbuthnot P (2007) Specific inhibition of HBV replication in vitro and in vivo with expressed long hairpin RNA. Mol Ther 15:534-541

Westerhout EM, Ooms M, Vink M, Das AT, Berkhout B (2005) HIV-1 can escape from RNA interference by evolving an alternative structure in its RNA genome. Nucleic Acids Res 33:796-804 
Westerhout EM, Vink M, Haasnoot PC, Das AT, Berkhout B (2006) A conditionally replicating HIV-based vector that stably expresses an antiviral shRNA against HIV-1 replication. Mol Ther 14:268-275

Wilson JA, Richardson CD (2005) Hepatitis C virus replicons escape RNA interference induced by a short interfering RNA directed against the NS5b coding region. J Virol 79:7050-7058

Wu CJ, Huang HW, Liu CY, Hong CF, Chan YL (2005a) Inhibition of SARS-CoV replication by siRNA. Antiviral Res 65:45-48

Wu HL, Huang LR, Huang CC, Lai HL, Liu CJ, Huang YT, Hsu YW, Lu CY, Chen DS, Chen PJ (2005b) RNA interference-mediated control of hepatitis B virus and emergence of resistant mutant. Gastroenterology 128:708-716

Xuan B, Qian Z, Hong J, Huang W (2006) EsiRNAs inhibit Hepatitis B virus replication in mice model more efficiently than synthesized siRNAs. Virus Res 118:150-155

Yang N, Kazazian HH Jr (2006) L1 retrotransposition is suppressed by endogenously encoded small interfering RNAs in human cultured cells. Nat Struct Mol Biol 13:763-771

Ying C, De Clercq E, Neyts J (2003) Selective inhibition of hepatitis B virus replication by RNA interference. Biochem Biophys Res Commun 309:482-484

Ying RS, Zhu C, Fan XG, Li N, Tian XF, Liu HB, Zhang BX (2007) Hepatitis B virus is inhibited by RNA interference in cell culture and in mice. Antiviral Res 73:24-30

Zamecnik PC, Stephenson ML (1978) Inhibition of Rous sarcoma virus replication and cell transformation by a specific oligodeoxynucleotide. Proc Natl Acad Sci USA 75:280-284

Zhang W, Yang H, Kong X, Mohapatra S, Juan-Vergara HS, Hellermann G, Behera S, Singam R, Lockey RF, Mohapatra SS (2005) Inhibition of respiratory syncytial virus infection with intranasal siRNA nanoparticles targeting the viral NS1 gene. Nat Med 11:56-62

Zhang Y, Li T, Fu L, Yu C, Li Y, Xu X, Wang Y, Ning H, Zhang S, Chen W, Babiuk LA, Chang Z (2004) Silencing SARS-CoV Spike protein expression in cultured cells by RNA interference. FEBS Lett 560:141-146

Zhou N, Fang J, Mukhtar M, Acheampong E, Pomerantz RJ (2004) Inhibition of HIV-1 fusion with small interfering RNAs targeting the chemokine coreceptor CXCR4. Gene Ther 11:1703-1712 